\title{
Correction to: Identifying miRNA synergism using multiple-intervention causal inference
}

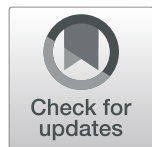

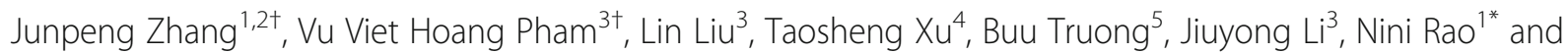
Thuc Duy Le $\mathrm{3}^{3^{*}}$

\section{Correction to: BMC Bioinformatics (2019) 20(Suppl} 23): 613

https://doi.org/10.1186/s12859-019-3215-5

After publication of this supplement article [1], it was brought to our attention that the Fig. 3 was incorrect. The correct Fig. 3 is as below:

\begin{abstract}
Author details
${ }^{1}$ Center for Informational Biology, School of Life Science and Technology, University of Electronic Science and Technology of China, Chengdu 610054, Sichuan, China. ${ }^{2}$ School of Engineering, Dali University, Dali 671003, Yunnan, China. ${ }^{3}$ School of Information Technology and Mathematical Sciences, University of South Australia, Mawson Lakes, SA 5095, Australia. Institute of Intelligent Machines, Hefei Institutes of Physical Science, Chinese Academy of Sciences, Hefei, China. ${ }^{5}$ Pham Ngoc Thach University of Medicine, Ho Chi Minh, Vietnam.
\end{abstract}

Published online: 29 January 2020

\section{Reference}

1. Zhang, et al. BMC Bioinformatics. 2019;20(Suppl 23):613. https://doi.org/10. 1186/s12859-019-3215-5.

The original article can be found online at https://doi.org/10.1186/s12859019-3215-5

*Correspondence: raonn@uestc.edu.cn; thuc.le@unisa.edu.au

${ }^{\dagger} J$ unpeng Zhang and Vu Viet Hoang Pham contributed equally to this work. ${ }^{1}$ Center for Informational Biology, School of Life Science and Technology, University of Electronic Science and Technology of China, Chengdu 610054, Sichuan, China

${ }^{3}$ School of Information Technology and Mathematical Sciences, University of South Australia, Mawson Lakes, SA 5095, Australia

Full list of author information is available at the end of the article

(c) The Author(s). 2020 Open Access This article is distributed under the terms of the Creative Commons Attribution 4.0 International License (http://creativecommons.org/licenses/by/4.0/), which permits unrestricted use, distribution, and reproduction in any medium, provided you give appropriate credit to the original author(s) and the source, provide a link to the Creative Commons license, and indicate if changes were made. The Creative Commons Public Domain Dedication waiver (http://creativecommons.org/publicdomain/zero/1.0/) applies to the data made available in this article, unless otherwise stated. 


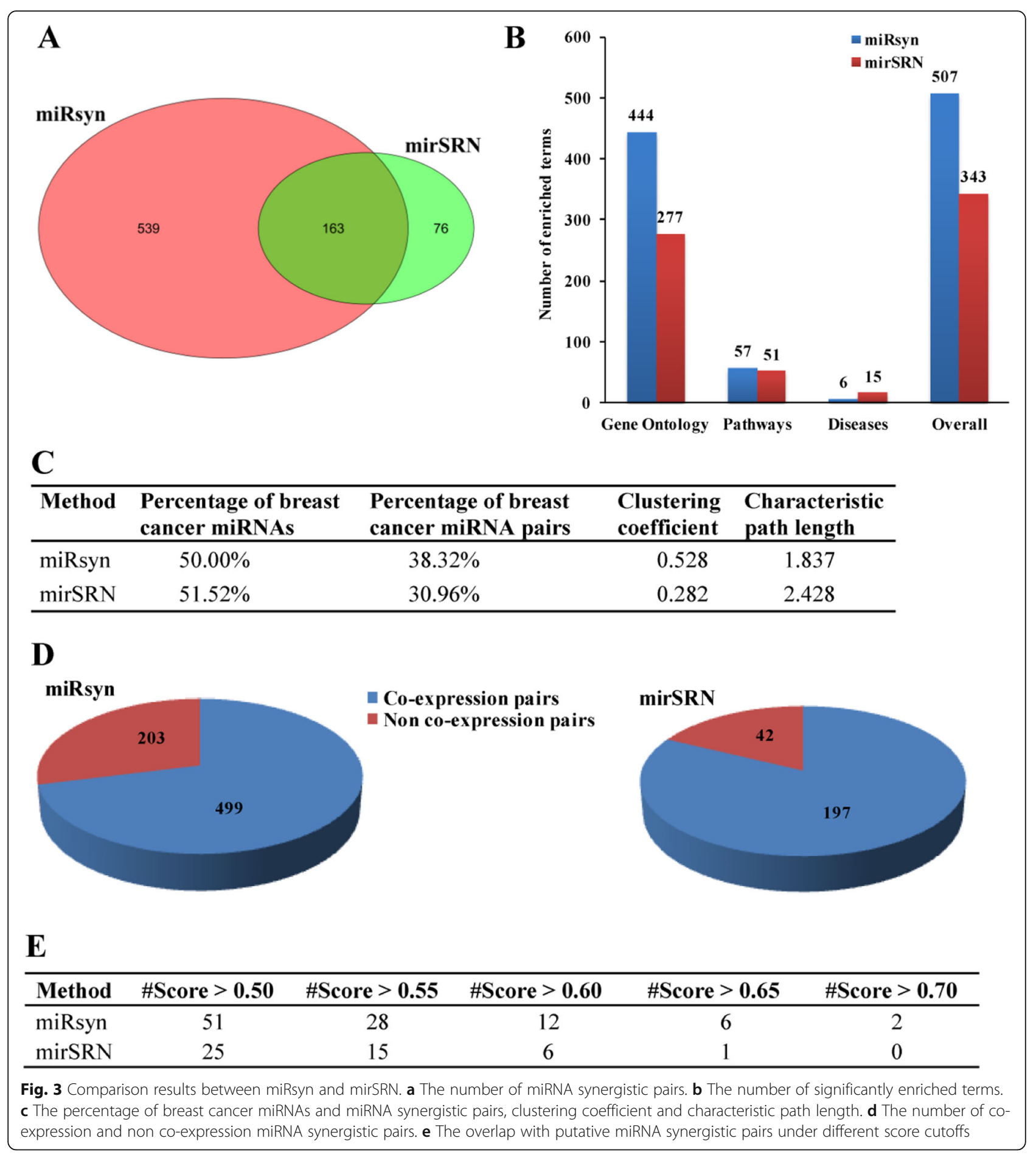

